\title{
Differences in Size at Birth Are Determined by Differences in Growth Velocity during Early Prenatal Life
}

\author{
SILVANO MILANI, ANNA BOSSI, ENRICO BERTINO, \\ ELIANA DI BATTISTA, ALESSANDRA COSCIA, GIORGIO AICARDI, CLAUDIO FABRIS, \\ AND LODOVICO BENSO
}

Istituto di Statistica Medica e Biometria [S.M., A.B.], Università degli Studi di Milano, 20133 Milano, Italy, Cattedra di Neonatologia [E.B., A.C., C.F.], S.C.D.U. di Auxologia [L.B.], Università degli Studi di Torino, 10126 Torino, Italy, Clinica Pediatrica I [E.D.B., G.A.], DIPE, Università degli Studi di Genova, 16148 Genova, Italy

\begin{abstract}
Physiologic interindividual differences in neonatal size are traditionally thought of as determined by differences in fetal growth occurring only in the second half of pregnancy. Whether possible differences in early intrauterine growth velocity are the effect of random growth fluctuations or may affect size at birth is still debated. This article aims at evaluating to what extent differences in neonatal size are accounted for by differences in fetal growth velocity. We analyzed the fetal growth of 130 healthy singletons for whom head (HC) and abdomen (AC) circumferences and femur diaphysis length (FDL) longitudinal profiles were available, together with the measures of weight (BW), length (BL), and head circumference (BHC) at birth. Individual profiles were fitted with ad-hoc models. Neonatal traits were transformed into standard deviation scores (SDS). Neonates in the upper third of BW-SDS distribution (3618 \pm $43 \mathrm{~g}$, mean $\pm \mathrm{SEM}$ ) had, at 22 wk of gestational age, AC growth velocity higher by $0.55 \pm 0.10 \mathrm{~mm} / \mathrm{wk}$ than those in the lower third $(2902 \pm 36 \mathrm{~g})$. Neonates in the upper third of BL-SDS distribution $(51.7 \pm 0.21 \mathrm{~cm})$ had, at $20 \mathrm{wk}$, FDL growth velocity higher by $0.11 \pm 0.05 \mathrm{~mm} / \mathrm{wk}$ than those in the lower third $(48.2 \pm 0.18 \mathrm{~cm})$. Neonates in the upper third of BHC-SDS
\end{abstract}

\section{ABSTRACT}

distribution $(35.7 \pm 0.13 \mathrm{~cm})$ had, at $18 \mathrm{wk}$, HC growth velocity higher by $0.57 \pm 0.20 \mathrm{~mm} / \mathrm{wk}$ than those in the lower third $(33.3$ $\pm 0.11 \mathrm{~cm})$. The differences in growth velocity remain constant throughout the second and third trimester for $\mathrm{AC}$, and tend to vanish in the third trimester for HC and FDL. The differences in fetal growth velocity, which in our study were observed as early as mo 4, suggest that the genetic component plays an important role in fetal growth and is precociously expressed. (Pediatr Res 57: 205-210, 2005)

$\quad$ Abbreviations
AC, abdomen circumference
BHC, head circumference at birth
BL, birth length
BPD, biparietal diameter
BW, birth weight
CRL, crown-rump length
FDL, femur diaphysis length
GA, gestational age
HC, head circumference
SDS, standard deviation score

Physiologic interindividual differences in neonatal size are traditionally thought of as determined by differences in fetal growth occurring only in the second half of pregnancy $(1,2)$. Actually, the assessment of GA derived from the measurement of CRL during the late first trimester (3), as well as of BPD, $\mathrm{HC}$, and FDL during the second trimester (4), rests on the assumption that in this period fetuses of the same size have nearly the same GA. Empirical evidence against the above assumption is unlikely to be provided, inasmuch as differences

Received March 30, 2004; accepted July 26, 2004.

Correspondence: Enrico Bertino, m.b., Cattedra di Neonatologia, Università degli Studi di Torino, Via Ventimiglia 3, 10126 Torino, Italy; e-mail: enrico.bertino@unito.it

DOI: 10.1203/01.PDR.0000148452.98518.D5 in size in the first half of pregnancy are expected to be small, growth being a cumulative process, and measurement error being relatively large with respect to size. On the other hand, negligible interindividual differences in size at a given gestational age do not necessarily imply negligible differences in growth velocity, which may be estimated only by means of longitudinal studies.

Longitudinal studies presently available, although based on few subjects and limited to the first trimester $(5,6)$, suggest that fetuses may differ in growth velocity of CRL, BPD, and average abdomen diameter already from the late first trimester. By contrast, Guihard-Costa et al. (7), on the basis of 24 pregnancies followed from the wk 7 up to delivery, asserts that 
differences in growth velocity emerge only during the third trimester. Whether possible differences in early intrauterine growth velocity are simply the effect of random growth fluctuations or, on the contrary, affect the size at birth is still a debated issue.

The aim of this study is to evaluate, on the basis of a large series of longitudinal observations taken from wk 12 to the end of gestation, how and to what extent physiologic interindividual differences in weight, length, and head circumference at birth are accounted for by differences in growth velocity of fetal AC, FDL, and HC.

\section{SUBJECTS AND METHODS}

Data here analyzed were collected during a prospective longitudinal survey, the Intrauterine and Infant Growth Longitudinal Study (IIGLS) $(4,8)$. The survey was carried out on pregnant women selected in Turin and Genoa, between 1987 and 1990, in accordance with the restrictive criteria recommended by the International Federation of Gynecology and Obstetrics (FIGO) (9), so as to include only normal singleton pregnancies. Informed consent was obtained from each mother participating in the survey.

The study was approved by the ethical committees of both the clinical institutions where data were collected. The series so obtained was made up of 238 neonates (123 females, 115 males) born at term after low-risk, uncomplicated pregnancy. Gestational age was estimated from the last menstrual period and was confirmed by an early ultrasound examination carried out within wk 12 , on the basis of the CRL (10). When the difference between the two estimates exceeded $7 \mathrm{~d}$, the pregnancy was excluded from the series.

Five one-dimensional traits were considered: BPD, occipitofrontal diameter (OFD), HC, AC, and FDL. Individual growth profiles consist of five to nine measures (totalling from 1539 scans for BPD to 1237 scans for AC), taken between gestational wk 12 and 40. Four trained echographers performed all measurements, by means of real-time scanners (Ansaldo AU920, ATL Ultramark IV, Toshiba SAL 30A) equipped with 3.5-MHz transducers. Further details on measurement techniques have been given previously (4). A short test-retest experiment was performed to estimate the comparability of measurements: 20 pregnant women with GA ranging from 13 to 36 wk (the same number of pregnancies was in the second and third trimester), were independently examined by two echographers. The mean measuring errors, expressed as $\mathrm{S}_{\text {meas }}$ (i.e. $\mathrm{SE}$ of measurements) and concerning the second and the third trimester, respectively, were as follows: 2.43 and $3.49(\mathrm{HC}), 4.02$ and 6.44 (AC), 0.74 and 0.88 (FDL).

Out of the IIGLS series, 130 subjects (68 females and 62 males) were selected according to the following criteria of inclusion: availability of HC, $\mathrm{AC}$, and FDL growth profiles; availability of the measures of BW, BL, and BHC.

The individual HC and FDL profiles were fitted with the log-count model (4), whereas AC profiles were fitted with the model of Todros et al. (11). Individual raw velocities were derived from each pair of measures taken 5-10 wk apart, and velocity residuals were computed as the difference between raw velocities and velocities predicted by individual curves. Neonatal traits were transformed into SDS on the basis of neonatal norms for northwest Italy (12). The tertiles of BW-SDS distribution, as well as those of HC-SDS and BL-SDS, were used as cut points to classify babies into three groups: low, mid, and high BW-SDS (or HC-SDS or BL-SDS). For each group, mean constant growth curves were computed, i.e. growth curves the constants of which are the averages of individual constants.

\section{RESULTS}

$\boldsymbol{B W}$ and fetal growth of $\boldsymbol{A C}$. Table 1 gives maternal and neonatal anthropometric characteristics, as well as fetal AC and $\mathrm{AC}$ velocity values at selected weeks of gestation, for the 130 babies classified by tertiles of the BW-SDS distribution: the lower third (43 subjects), the mid third (44 subjects), and the upper third (43 subjects). For these three groups, Figure 1 shows fetal AC and AC growth velocity from wk 13 to the end of gestation. The difference in BW between the upper and lower BW-SDS groups is $716 \pm 56 \mathrm{~g}(1.73 \pm 0.09 \mathrm{BW}-\mathrm{SDS})$. Wide differences also exist in BL-SDS $(0.92 \pm 0.18)$ and BHC-SDS $(0.69 \pm 0.21)$. Compared with the babies in the lower BW-SDS group, those in the upper BW-SDS group had higher placental weight (by $140 \pm 21 \mathrm{~g}$ ) and mothers with slightly heavier body weight before pregnancy (by $3.9 \pm 1.9$ $\mathrm{kg}$ ). No significant difference appears in maternal height and weight gain during pregnancy. The gap in $\mathrm{AC}$ between the upper and lower BW-SDS groups largely increases with in-

Table 1. Maternal and neonatal anthropometric characteristics, and fetal abdomen circumference of babies classified by tertiles of the distribution of birthweight-SDS

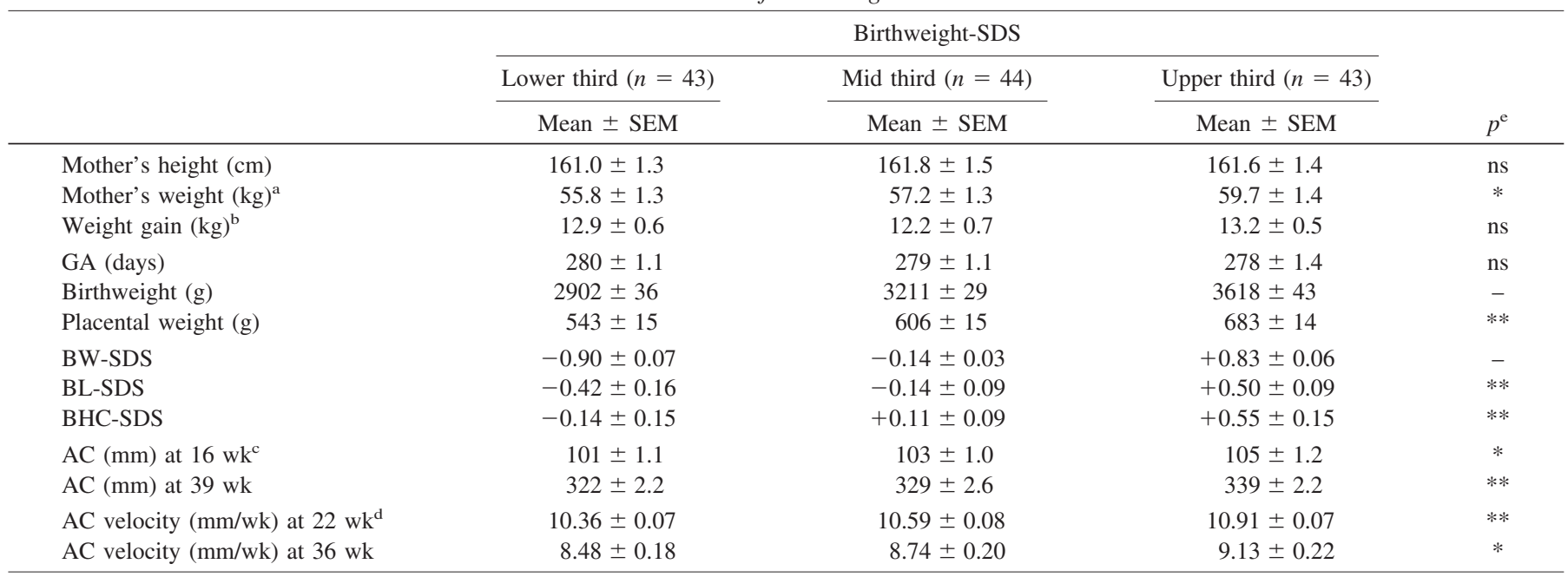

${ }^{\text {a }}$ Before pregnancy.

${ }^{\mathrm{b}}$ At the end of pregnancy.

${ }^{c}$ Age at which the differences in fetal abdomen circumference become detectable.

${ }^{\mathrm{d}}$ Age at peak velocity of fetal abdomen circumference.

${ }^{\mathrm{e}}$ Difference between upper and lower tertile: ns, not significant; $* p<0.05$, $* * p<0.01$. 


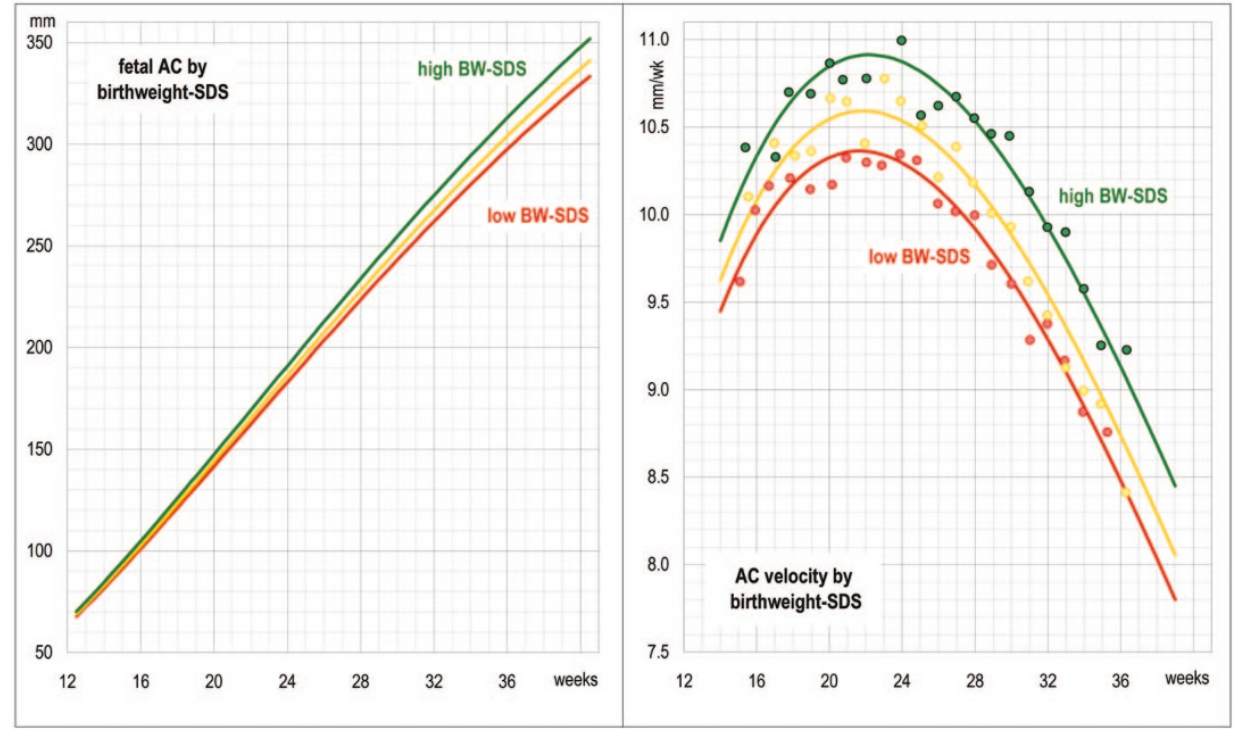

Figure 1. Fetal size (left) and growth velocity (right) of AC from wk 13 to the end of gestation in a set of 130 babies classified by tertiles of the BW-SDS distribution: lower third (red, 43 babies), mid-third (yellow, 44), upper third (green, 43). Circles represent the average of velocity residuals at each week of gestation.

creasing GA: from $4.0 \pm 1.6 \mathrm{~mm}$ at $16 \mathrm{wk}$ to $12 \pm 3.1$ at 32 wk, and to $17 \pm 3.1$ at 39 wk. This is the effect of a nearly constant difference in AC velocity: $0.55 \pm 0.10 \mathrm{~mm} / \mathrm{wk}$ at the moment of peak velocity (about $22 \mathrm{wk}$ for all the three groups), and $0.65 \pm 0.28 \mathrm{~mm} / \mathrm{wk}$ at $36 \mathrm{wk}$.

BL and fetal growth of FDL. Table 2 gives maternal and neonatal characteristics, as well as fetal FDL and FDL velocity values, for the babies classified by tertiles of the BL-SDS distribution. For these three groups, Figure 2 shows fetal FDL and FDL growth velocity.

The difference in BL between the upper and lower BL-SDS groups is $3.5 \pm 0.28 \mathrm{~cm}(1.76 \pm 0.11 \mathrm{BL}-\mathrm{SDS})$. Wide differences also exist in BW-SDS (1.08 \pm 0.16$)$ and BHC-SDS
(0.56 \pm 0.19$)$. Compared with the babies in the lower BL-SDS group, those in the upper BL-SDS group had higher placental weight (by $94 \pm 25 \mathrm{~g}$ ) and mothers with slightly heavier body weight before pregnancy (by $3.9 \pm 1.8 \mathrm{~kg}$ ). No significant difference emerges in mother's height and weight gain during pregnancy. The gap in FDL between the upper and lower BL-SDS groups increases mainly during late second and early third trimesters: from $1.1 \pm 0.47 \mathrm{~mm}$ at $22 \mathrm{wk}$ to $2.1 \pm 0.41$ at $32 \mathrm{wk}$ and $2.4 \pm 0.63$ at $39 \mathrm{wk}$. This is the effect of the difference in FDL velocity, which reaches its maximum $(0.11$ $\pm 0.05 \mathrm{~mm} / \mathrm{wk}$ ) at the moment of peak velocity (about $20 \mathrm{wk}$ ), and then declines slowly, becoming only $0.05 \pm 0.28 \mathrm{~mm} / \mathrm{wk}$ at $36 \mathrm{wk}$.

Table 2. Maternal and neonatal anthropometric characteristics, and fetal femur diaphysis length of babies classified by tertiles of the distribution of birthlength-SDS

\begin{tabular}{|c|c|c|c|c|}
\hline & \multicolumn{3}{|c|}{ Birthlength-SDS } & \multirow[b]{3}{*}{$p^{\mathrm{e}}$} \\
\hline & \multirow{2}{*}{$\frac{\text { Lower third }(n=43)}{\text { Mean } \pm \text { SEM }}$} & \multirow{2}{*}{$\begin{array}{c}\text { Mid third }(n=44) \\
\text { Mean } \pm \text { SEM }\end{array}$} & \multirow{2}{*}{$\begin{array}{c}\text { Upper third }(n=43) \\
\text { Mean } \pm \text { SEM }\end{array}$} & \\
\hline & & & & \\
\hline Mother's weight $(\mathrm{kg})^{\mathrm{a}}$ & $56.3 \pm 1.1$ & $56.3 \pm 1.4$ & $60.2 \pm 1.4$ & $*$ \\
\hline Weight gain $(\mathrm{kg})^{\mathrm{b}}$ & $13.3 \pm 0.7$ & $12.5 \pm 0.6$ & $12.3 \pm 0.5$ & $\mathrm{~ns}$ \\
\hline GA (days) & $278 \pm 1.2$ & $281 \pm 1.0$ & $279 \pm 1.4$ & ns \\
\hline BW-SDS & $-0.55 \pm 0.10$ & $-0.17 \pm 0.08$ & $+0.53 \pm 0.12$ & $* *$ \\
\hline BL-SDS & $-0.93 \pm 0.07$ & $+0.03 \pm 0.03$ & $+0.83 \pm 0.08$ & - \\
\hline BHC-SDS & $-0.12 \pm 0.13$ & $+0.24 \pm 0.13$ & $+0.44 \pm 0.14$ & $* *$ \\
\hline FDL $(\mathrm{mm})$ at $22 \mathrm{wk}^{\mathrm{c}}$ & $37.8 \pm 0.31$ & $38.2 \pm 0.30$ & $38.9 \pm 0.35$ & $*$ \\
\hline FDL $(\mathrm{mm})$ at $39 \mathrm{wk}$ & $69.9 \pm 0.46$ & $70.9 \pm 0.56$ & $72.3 \pm 0.43$ & $* *$ \\
\hline
\end{tabular}

${ }^{\text {a }}$ Before pregnancy.

${ }^{\mathrm{b}}$ At the end of pregnancy.

${ }^{\mathrm{c}}$ Age at which the differences in fetal femur diaphysis length become detectable.

${ }^{\mathrm{d}}$ Age at peak velocity of fetal femur diaphysis length.

${ }^{\mathrm{e}}$ Difference between upper and lower tertile: ns, not significant; $* p<0.05, * * p<0.01$. 


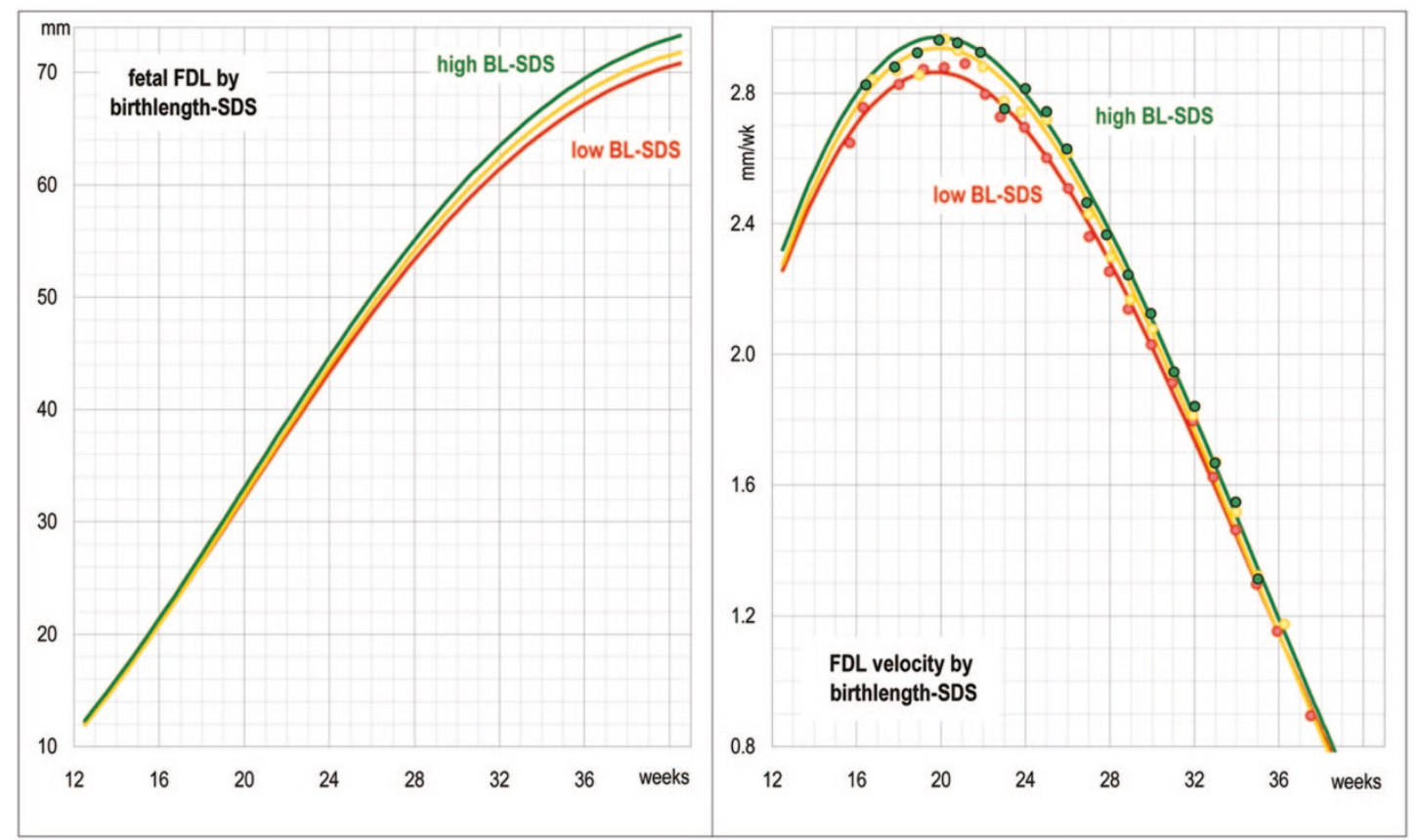

Figure 2. Fetal size (left) and growth velocity (right) of FDL from wk 13 to the end of gestation in a set of 130 babies classified by tertiles of the BL-SDS distribution: lower third (red, 43 babies), mid-third (yellow, 44), upper third (green, 43). Circles represent the average of velocity residuals at each week of gestation.

Table 3. Maternal and neonatal anthropometric characteristics, and fetal head circumference of babies classified by tertiles of the distribution of head circumference-SDS at birth

\begin{tabular}{|c|c|c|c|c|}
\hline & \multicolumn{3}{|c|}{ Head circumference-SDS at birth } & \multirow[b]{3}{*}{$p^{\mathrm{e}}$} \\
\hline & \multirow{2}{*}{$\frac{\text { Lower third }(n=43)}{\text { Mean } \pm \text { SEM }}$} & \multirow{2}{*}{$\begin{array}{c}\text { Mid third }(n=44) \\
\text { Mean } \pm \text { SEM }\end{array}$} & \multirow{2}{*}{$\frac{\text { Upper third }(n=43)}{\text { Mean } \pm \text { SEM }}$} & \\
\hline & & & & \\
\hline Mother's weight $(\mathrm{kg})^{\mathrm{a}}$ & $57.7 \pm 1.2$ & $56.8 \pm 1.3$ & $58.5 \pm 1.6$ & $\mathrm{~ns}$ \\
\hline Weight gain $(\mathrm{kg})^{\mathrm{b}}$ & $11.9 \pm 0.6$ & $12.7 \pm 0.6$ & $13.7 \pm 0.6$ & $*$ \\
\hline GA (days) & $278 \pm 0.9$ & $279 \pm 1.3$ & $281 \pm 1.4$ & ns \\
\hline BW-SDS & $-0.42 \pm 0.11$ & $-0.04 \pm 0.11$ & $+0.26 \pm 0.12$ & $* *$ \\
\hline BL-SDS & $-0.32 \pm 0.13$ & $+0.01 \pm 0.12$ & $+0.22 \pm 0.13$ & $* *$ \\
\hline BHC-SDS & $-0.77 \pm 0.08$ & $+0.16 \pm 0.03$ & $+1.14 \pm 0.08$ & - \\
\hline $\mathrm{HC}(\mathrm{mm})$ at $21 \mathrm{wks}^{\mathrm{c}}$ & $183 \pm 1.1$ & $186 \pm 1.3$ & $187 \pm 1.2$ & $*$ \\
\hline $\mathrm{HC}(\mathrm{mm})$ at $39 \mathrm{wks}$ & $331 \pm 1.9$ & $335 \pm 1.9$ & $339 \pm 1.6$ & $* *$ \\
\hline
\end{tabular}

${ }^{\text {a }}$ Before pregnancy.

${ }^{\mathrm{b}}$ At the end of pregnancy.

${ }^{\mathrm{c}}$ Age at which the differences in fetal head circumference become detectable.

${ }^{\mathrm{d}}$ Age at peak velocity of fetal head circumference.

${ }^{\mathrm{e}}$ Difference between upper and lower tertile: ns, not significant; $* p<0.05$, ** $p<0.01$.

BHC and fetal growth of $\boldsymbol{H C}$. Table 3 gives maternal and neonatal characteristics, as well as fetal $\mathrm{HC}$ and $\mathrm{HC}$ velocity values, for the babies classified by tertiles of the distribution of BHC-SDS. For these three groups, Figure 3 shows fetal $\mathrm{HC}$ and $\mathrm{HC}$ growth velocity. The difference in BHC between the upper and lower BHC-SDS groups is $2.4 \pm 0.17$ $\mathrm{cm}$ (1.91 \pm 0.11 BHC-SDS). Differences also exist in BW-SDS (0.68 \pm 0.16$)$ and BL-SDS (0.54 \pm 0.18$)$. Compared with the babies in the lower BHC-SDS group, those in the upper BL-SDS group had higher placental weight (by
$89 \pm 23 \mathrm{~g}$ ) and mothers with larger weight gain during pregnancy (by $1.8 \pm 0.8 \mathrm{~kg}$ ). No significant difference was observed in maternal weight before pregnancy and height.

The gap in HC between the upper and lower BHC-SDS groups increases during late second and early third trimesters: from $4 \pm 1.6 \mathrm{~mm}$ at $21 \mathrm{wk}$ to $8 \pm 1.5$ at $32 \mathrm{wk}$ and $8 \pm 2.5$ at $39 \mathrm{wk}$. This is the effect of the difference in $\mathrm{HC}$ velocity, which reaches its maximum $(0.57 \pm 0.20 \mathrm{~mm} / \mathrm{wk})$ at the moment of peak velocity (about $18 \mathrm{wk}$ ), and then declines, becoming negligible at $36 \mathrm{wk}$. 


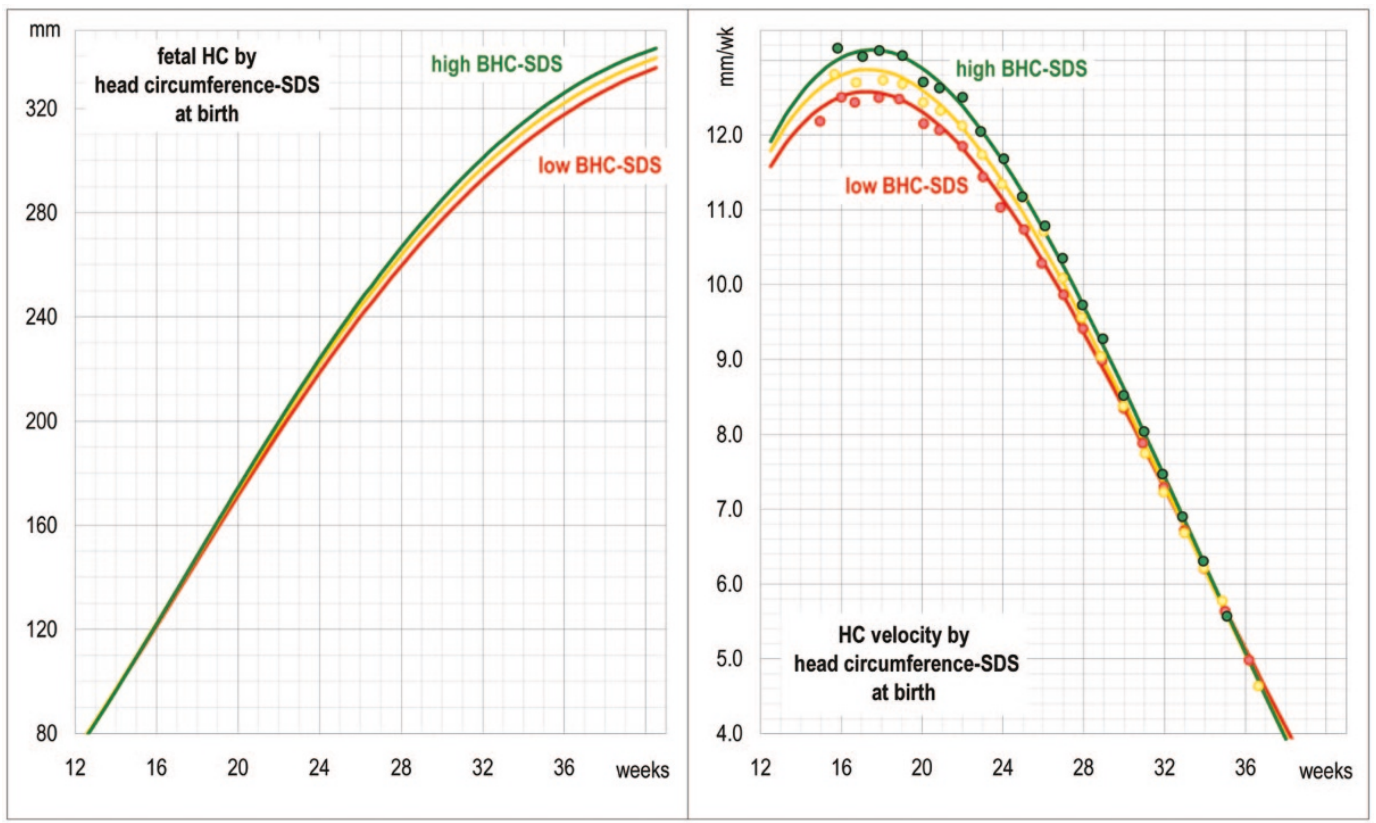

Figure 3. Fetal size (left) and growth velocity (right) of HC from wk 13 to the end of gestation, in a set of 130 babies classified by tertiles of the HC-SDS distribution at birth: lower third (red, 43 babies), mid-third (yellow, 44), upper third (green, 43). Circles represent the average of velocity residuals at each week of gestation.

\section{DISCUSSION}

The evaluation of fetal growth kinetics in a set of 130 physiologic pregnancies, followed-up longitudinally from wk 12 to delivery, allows us to conclude that larger neonates have higher growth velocity of one-dimensional traits (AC, FDL, HC) during early prenatal life. The differences in fetal growth velocity between larger and smaller neonates are already apparent between mo 4 and 5 of pregnancy, when the interindividual differences in the size of these traits can hardly be detected.

Subsequently, the difference in fetal growth velocity of AC remains nearly constant so that the differences in size progressively increase. By contrast, the difference in fetal growth velocity of $\mathrm{HC}$ and FDL tends to vanish in the late third trimester, so that the differences in size remain nearly constant.

The above differences are not an artifact due to the rigid shape of the log-count model or the model of Todros et al. Actually, there is a fair concordance between mean raw velocities and velocities predicted by models (Figs. 1-3, right), even within wk 20 of gestation, where about 100 raw estimates of growth velocity are available. Nonetheless, the fair internal consistency of these results may appear to be weakened, to some extent, by two drawbacks. The first is that the mean difference in $\mathrm{HC}$ at $39 \mathrm{wk}(0.8 \pm 0.25 \mathrm{~cm})$ between the upper and lower third of BHC-SDS distribution accounts only in part for a difference of $2.4 \pm 0.2 \mathrm{~cm}$ in $\mathrm{HC}$ at birth. The second is that the mean difference in FDL at 39 wk $(0.24 \pm 0.06 \mathrm{~cm})$ between the upper and lower third of BL-SDS distribution does not account for a difference of $3.5 \pm 0.3 \mathrm{~cm}$ in BL. As to the first point, the weak correlation between fetal size at the end of pregnancy and size at birth could be due to unpredictable changes in fetal growth velocity during the final 2-4 wk of gestation in some subjects (7), to the error of measurement of both prenatal and neonatal traits, as well as to the fact that prenatal and neonatal head circumference values are assessed with very different techniques. As to the second point, FDL and BL are not expected to be strictly correlated since, at birth, femural length is only $1 / 7$ th of total length.

Generally, small fetal size in the late first trimester and small size at birth were found to be related only in nonphysiological conditions. Smith et al. (13), comparing a group of 1289 fetuses with a smaller than expected CRL to a group of 2108 normal or larger than expected CRL (with measures taken wk 12 , on the average), noticed that the relative risk for BW below the 5th centile is 2.8 (95\% confidence limits, $1.9-4.3$ ). Abnormally low values of CRL in early pregnancy (within wk 14) are reported to be associated with small-for-gestational-age (SGA) neonates in 35 diabetic pregnancies (14) as well as in 107 threatened abortions (15). More recently, Kalish et al. (16) observed that BW discordance in 16 pairs of dichorionic twins correlates with differences in CRL between 11 and 14 wk of gestation. These results are largely in agreement with our observation that differences in growth velocity occur even in the first months of pregnancy. The studies here mentioned deal only with BW: our study showed that also the physiologic differences in HC and FDL growth velocity, which are already apparent at the end of the first trimester, may predict differences in head circumference and body length at birth. Interindividual differences in fetal size during the early second trimester of physiologic pregnancies are considered negligible, mainly as regards BPD and, to a lesser extent, FDL $(3,17)$. On the basis of these considerations, the ultrasound assessment of BPD and FDL is still recommended to determine GA, even in the second trimester $(3,18)$. An increase in these differences during the second and third trimesters was observed in nonphysiological pregnancies with symmetric or asymmetric SGA 
outcome (19), as well as with adverse outcome, such as preterm birth, perinatal death, low BW, and SGA (20).

During the early fetal period, physiologic differences in size are expected to be small. In this regard, a recent study, carried out by Hindmarsh et al. (21) on 1218 low-risk, uncomplicated pregnancies with at term outcome, showed that neonatal size is poorly correlated to BPD, FDL, and abdomen diameter, both at 20 and 30 wk of gestation. This latter study and those referenced above do not answer the basic question addressed here: whether the differences in growth velocity during the second or third trimester in this period are also negligible.

According to Smith et al. (13) and Nakling et al. (20), the reasons for a causal relationship between poor first trimester growth and low BW may be either suboptimal environment or suboptimal transfer of nutrients to the fetus. Alternatively, some fetuses may be physiologically small throughout pregnancy. In our study, we included only healthy pregnancies, as Smith et al. (13) did, but as a further criterion of inclusion we considered only full-term, appropriate for GA neonates. Thus, the differences here observed can be safely ascribed to early physiologic variability.

Fetal growth depends upon a complex interaction between stimulating or inhibiting genetic and environmental factors, but the amount of the contribution of either factors to final fetal size is still unclear. It is not known when and to what extent genetic regulating factors begin to be expressed, nor when and to what extent the environment, which is also of maternal origin and mostly restrictive in nature, begins to modify the effects of genetic factors. Because the size of placenta and uterus in the first part of pregnancy is by far larger than fetal size, its effect on fetal growth is likely to be lower than in the second part (2).

The differences in fetal growth velocity, which in our study were observed as early as mo 4, and the effects of which were still apparent at the end of pregnancy, suggest that the genetic component plays an important role in fetal growth and is precociously expressed. Our study did not allow us to evaluate the effects of environment on final size, inasmuch as we had no data on uterus size nor direct indicators of the efficiency of transfer of nutrients to the fetus. Nonetheless, lighter fetuses had lighter placentas, as one could expect because the placenta is an organ of embryonic origin. This might suggest that genetic factors determine, at least in part, the environmental condition suitable for their expression up to the end of pregnancy.

\section{REFERENCES}

1. Gluckman PD, Liggings GC 1984 Regulation of fetal growth. In: Beard RW, Nathanielsz PW (eds) Fetal Physiology and Medicine: The Basis of Perinatology, 2nd Ed, Vol VI. Marcel Dekker, New York, pp 511-558

2. Carrera JM, Devesa R, Carrera M, Serra B 1998 Regulating factors. In: Kurjak A (ed) Textbook of Perinatal Medicine. Parthenon Publishing Group Ltd, London, pp 1132-1139

3. Degani S 2001 Fetal biometry: clinical, pathological, and technical considerations. Obstet Gynecol Surv 56:159-167

4. Bertino E, Di Battista E, Bossi A, Pagliano M, Fabris C, Aicardi G, Milani S 1996 Fetal growth velocity: kinetic, clinical, and biological aspects. Arch Dis Child 74:F10-F15

5. Blaas HG, Eik-Nes SH, Bremnes JB 1998 The growth of the human embryo. A longitudinal biometric assessment from 7 to 12 weeks of gestation. Ultrasound Obstet Gynecol 12:346-354

6. Deter RL, Buster JE, Casson PR, Carson SA 1999 Individual growth patterns in the first trimester: evidence for difference in embryonic and fetal growth rates. Ultrasound Obstet Gynecol 13:90-98

7. Guihard-Costa AM, Droullé P, Thiebaugeorges O, Hascoet JM 2000 A longitudinal study of fetal growth variability. Biol Neonate 78:8-12

8. Benso L, Aicardi G, Fabris C, Milani S 1999 What longitudinal studies can tell us about fetal growth. In: Johnston FE, Zemel B, Eveleth P (eds) Human Growth in Context. Smith-Gordon, London, pp 41-50

9. International Federation of Gynecology and Obstetrics (FIGO) Sub-committee on Perinatal Epidemiology and Health Statistics 1984 Report of the committee following a workshop on the methodology of measurement and recording of infant growth in the perinatal period. FIGO, London

10. Robinson HP 1973 Sonar measurement of fetal crown-rump length as means of assessing maturity in first trimester of pregnancy. BMJ 4:28-31

11. Todros T, Ferrazzi E, Groli C, Nicolini U, Parodi L, Pavoni M, Zorzoli A, Zucca S 1987 Fitting growth curves to head and abdomen measurements of the fetus: a multicentric study. J Clin Ultrasound 15:95-105

12. Bertino E, Murru P, Bagna R, Ventriglia A, Garzena E, Martano C, Prandi G, Costa S, Borgione G, Milani S, Fabris C 1999 Standard antropometrici neonatali dell'Italia Nord-Occidentale. Riv Ital Pediatr 25:899-906

13. Smith GCS, Smith MFS, McNay MB, Fleming JEE 1998 First-trimester growth and the risk of low birth weight. N Engl J Med 339:1817-1822

14. Pedersen JF, Mølsted-Pedersen L 1979 Early growth retardation in diabetic pregnancy. BMJ 1:18-19

15. Reljič M 2001 The significance of crown-rump length measurement for predicting adverse pregnancy outcome of threatened abortions. Ultrasound Obstet Gynecol 17:510-512

16. Kalish RB, Chasen ST, Gupta M, Sharma G, Perni SC, Chervenak FA 2003 First trimester prediction of growth discordance in twin gestations. Am J Obstet Gynecol 189:706-709

17. Mul T, Mongelli M, Gardosi J 1996 A comparative analysis of second-trimester ultrasound dating formulae in pregnancies conceived with artificial reproductive techniques. Ultrasound Obstet Gynecol 8:397-402

18. Mongelli M, Yuxin NG, Biswas A, Chew S 2003 Accuracy of ultrasound dating formulae in the late second-trimester in pregnancies conceived with in-vitro fertilization. Acta Radiol 44:452-455

19. Vik T, Vatten L, Jacobsen G, Bakketeig LS 1997 Prenatal growth in symmetric and asymmetric small-for-gestational-age infants. Early Hum Dev 48:167-176

20. Nakling J, Backe B 2002 Adverse obstetric outcome in fetuses that are smaller than expected at second trimester routine ultrasound examination. Acta Obstet Gynecol Scand 81:846-851

21. Hindmarsh PC, Geary MPP, Rodeck CH, Kingdom JCP, Cole TJ 2002 Intrauterine growth and its relationship to size and shape at birth. Pediatr Res 52:263-268 